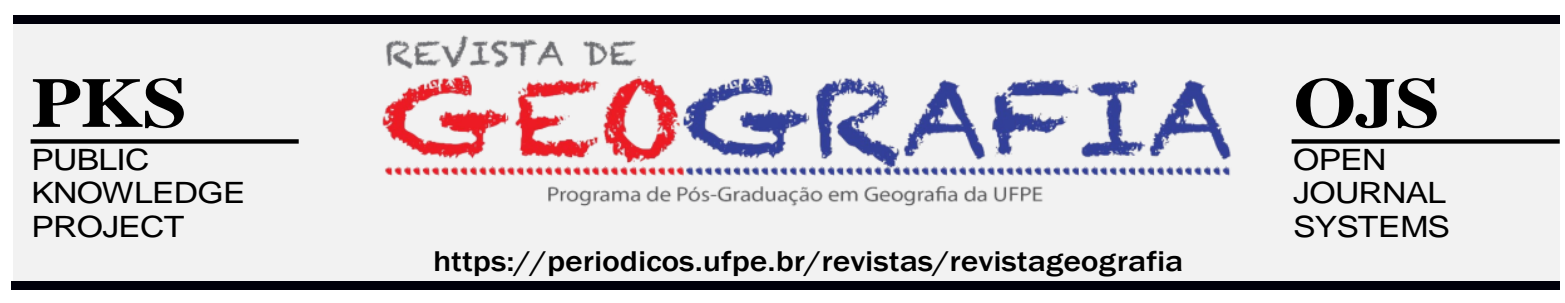

\title{
REPRESENTAÇÕES DAS PAISAGENS E DEMARCAÇÕES HIDROTERRITORIAIS DO RIO TIMBÓ (PE) E SUAS MARGENS NO APLICATIVO INSTAGRAM
}

\author{
Caio Augusto Amorim Maciel ${ }^{1}$, Jeovane da Silveira Fidelis Querino²
}

\begin{abstract}
1 Graduado em Agronomia pela Universidade Federal Rural de Pernambuco, Mestre em Geografia pela Universidade Federal de Pernambuco, Doutor em Geografia pela Universidade Federal do Rio de Janeiro, com Doutorado-sanduíche na França (Université de Pau et des Pays de l'Adour).E-mail: camorim3@terra.com.br ${ }^{2}$ Graduando em Licenciatura em Geografia, Petiano no grupo PET Conexões dos Saberes Encontros Sociais, Membro do Laboratório de estudos sobre Espaço, Cultura e Política (LECgeo), Departamento de Ciências Geográficas, Universidade Federal de Pernambuco (UFPE), Brasil. E-mail: jeovanedasilveira@gmail.com
\end{abstract}

Artigo recebido em 11/03/2020 e aceito em 17/03/2020

\begin{abstract}
RESUMO
O Instagram é um aplicativo de compartilhamento de fotos, vídeos e imagens, que vem se tornando bastante utilizado pelos seus usuários, desde sua origem em 2010. Este artigo analisa representações paisagísticas e demarcações territoriais e simbólicas concebidas pelas fotos no Instagram que retratam a geografia do rio Timbó (PE) e as suas margens. Desta forma, utilizou-se para fins metodológicos: o conceito de hidroterritório de Avaní Torres, o de paisagem segundo Jean-Marc Besse e da análise do poder simbólico segundo Pierre Bourdieu. Consequentemente, foram analisados os discursos fotográficos e a apropriação simbólica que as fotos exercem, desvelando as concepções territoriais, as representações e a estetização das paisagens. Com isso, mostra-se a importância da articulação dos conceitos geográficos de hidroterritório e paisagem para explicar a relação entre o virtual e o geográfico no mundo contemporâneo, bem como o poder simbólico da visibilidade nas postagens no aplicativo, promovendo um estudo visual da espacialidade do rio Timbó e suas margens.
\end{abstract}

Palavras-chave: Rio Timbó. Instagram. Hidroterritório. Paisagem.

\section{LANDSCAPE REPRESENTATIONS AND HYDRO-TERRITORIAL DEMARCATIONS OF THE TIMBÓ RIVER (PE) AND ITS MARGINS IN THE INSTAGRAM APPLICATION}

\begin{abstract}
Instagram is an application for sharing photos, videos and images, which has become widely used by its adherents, since its origin in 2010. This article analyzes the landscape representations and the territorial and symbolic conceptions conceived by the photos in the Instagram, which portray the geography of the Timbó river (PE) and its banks. In this way, it was used for methodological purposes: the Avaní Torres hydroterritory concept, the landscape concept according to Jean-Marc Besse and the analysis of symbolic power as stated by Pierre Bourdieu. Consequently, the photographic discourses and the symbolic appropriation that the photos exercise were analyzed, revealing the territorial demarcations and conceptions, the photographic representations and the aestheticization of the landscapes. This shows the importance of articulating geographic concepts of hydroterritory and landscape to explain the relationship between the virtual and the geographic in the contemporary world, as well as the symbolic power of the visibility of Instagram posts, promoting a visual study of the spatiality of the Timbó river and its margins.
\end{abstract}

Keywords: Timbó river. Instagram. Hydroterritory. Landscape. 


\section{INTRODUÇÃO}

O Instagram é uma rede social que ao longo dos anos vem crescendo em uso ao redor do mundo inteiro; a origem do seu nome se deve à junção dos verbetes em inglês, instant (instantâneo) e telegram (telegrama, do grego tele-, "longe", mais gramma, "letra do alfabeto", "mensagem", "informação"), sendo criado em outubro de 2010 por Kevin Systrom e Mike Krieger. O aplicativo surgiu com a função de compartilhamento de fotos online, no intuito de promover a junção das funções da fotografia e da instantaneidade das redes, atuando no entrelaçamento de duas mídias, a fotografia e o telegrama (SILVEIRA, 2017).

Este trabalho analisa as fotos dos usuários do Instagram, com alguns dos seus discursos fotográficos - que consistem no "entrelaçamento da linguagem e da sociedade atravessados pelo contexto social, político ou cultural” (BIANCHI, 2017, p. 54) - para relacionar como essas narrativas são atravessadas pelo contexto das representações paisagísticas e concepções hidroterritoriais e simbólicas do rio Timbó. Almeja-se interpretar a construção discursiva e a apropriação simbólica na demarcação do hidroterritório, a partir das relações de poder simbólico, bem como a estetização das paisagens do rio Timbó e suas margens, avaliando uma geografia instagramável (do Instagram) ${ }^{1}$.

O conceito de hidroterritório é definido por Avani Torres como "aquele território demarcado por questões de poder político e/ou cultural oriundo da gestão da água, assumindo assim, o papel determinante em sua ocupação" (TORRES, 2007, p. 14). Desta forma, se analisou como o poder político e cultural, que permeia as fotos instagramáveis, pode abranger as intencionalidades de alguns usuários do aplicativo, bem como o envolvimento desse poder político e cultural para demarcar hidroterritorialmente o rio.

A paisagem, segundo Jean-Marc Besse, pode ser "compreendida menos como um objeto do que como uma representação, um valor, uma dimensão do discurso e da vida humana, ou ainda, uma formação cultural" (BESSE, 2006, p. 78). Desta forma, o trabalho busca entender que a paisagem representada no Instagram pode ser interpretada por discursos fotográficos dos usuários do aplicativo.

\footnotetext{
${ }^{1}$ Este artigo incorpora reflexões apresentadas durante o II GIS Day UFPE (2019). Agradecemos a valiosa interlocução com os professores Fabrízio Rosito Listo, Lucas Cavalcanti, Priscila Batista Vasconcelos e Rodrigo Dutra.
} 
O referencial teórico do trabalho apoia-se ainda em contribuições de Gilles Lipovetski e Jean Serroy (2015) sobre as formas de manifestação do capitalismo artista e estético; Pierre Bourdieu (2001) no apontamento do poder simbólico; Manuela Salazar (2017) direcionando a questão da estetização do cotidiano pelo Instagram; Ana Clara Bianchi (2017) apontando os discursos fotográficos do Instagram como forma de entendimento das territorialidades dos usuários do Instagram.

Parte-se de Pierre Bourdieu (2001) para investigar os discursos fotográficos do Instagram e suas intencionalidades em relação ao rio Timbó e suas margens, de modo a detectar as diferentes concepções desse hidroterritório (efêmeras e cotidianas), revelando o rio em suas relações de poder simbólico, numa interação com o espaço virtual, para desvelar a construção da geografia do rio através da fotografia inserida no Instagram, como aponta Bianchi (2017): “A fotografia, nós dissemos, não é apenas instrumento que retrata a realidade, mas que a produz. É um instrumento de poder simbólico" (BIANCHI, 2017, p.120).

Busca-se, assim, articular os aspectos políticos e culturais, para entender a hidroterritorialidade do rio Timbó, na perspectiva de pensar o rio e suas paisagens como produto dos discursos fotográficos instagramáveis e a implicação desses na produção de representações geográficas.

\section{ÁREA DE ESTUDO}

O rio Timbó está localizado no norte da Região Metropolitana do Recife e pertence à Bacia Hidrográfica do Grupo de Pequenos Rios Litorâneos 1 (GL-1); este grupo comporta 7 sub-bacias (a do rio Arataca, do rio Botafogo, do rio Jaguaribe, do rio Igarassu, do rio Timbó, do rio Paratibe e do rio Beberibe). O Timbó é considerado um rio estuarino (OLIVEIRA BARBOSA, 2006), tanto é que sua denominação oficial é "Estuário do Rio Timbó", sendo este, conforme Oliveira Barbosa (idem), classificado em zonas estuarinas:

- Inferior: que vai da desembocadura até a restinga arenosa de Maria Farinha;

- Média: que vai da restinga de Maria Farinha até a jusante da Ilha central de mangue (que está entre Abreu e Lima, Paulista e Igarassu);

- Superior: que está localizada a montante da ilha central de mangue, que é uma região com canais separados por bancos arenosos, ilhas e baixios de maré.

As zonas estuarinas inferior e média são as mais utilizadas pelas atividades turísticas, pesqueiras, comerciais e urbanas, por isso são mais visibilizadas e usadas esteticamente no Instagram. Isto se deve, também, ao fator natural da influência das marés, que proporcionam a 
navegação de caiaques, lanchas, jet-skis e barcos na zona estuarina inferior e média, além da proximidade de praias com grande fluxo de turismo e lazer.

Já na zona estuarina superior, devido à alta incidência de bancos de areia, quando às marés estão baixas, não há uma presença significativa de lanchas, marinas, hotéis, barcos e caiaques, somente há a presença, próximos às margens do rio, das comunidades de Porto Jatobá e Cuieiras, bem como as ruínas da antiga Igreja de São Bento e da antiga Fazenda de São Bento de Jaguaribe, visualizados durante os trabalhos de campo (que se deram entre os meses de fevereiro e março de 2019) na área.

Nesse contexto, o Rio Timbó (Figura 1) é localizado na zona norte da Região Metropolitana de Recife, entre os municípios de Paulista, Abreu e Lima e Igarassu, na região do Litoral Norte do Estado de Pernambuco.

Figura 1: Mapa de Localização do rio Timbó (PE)

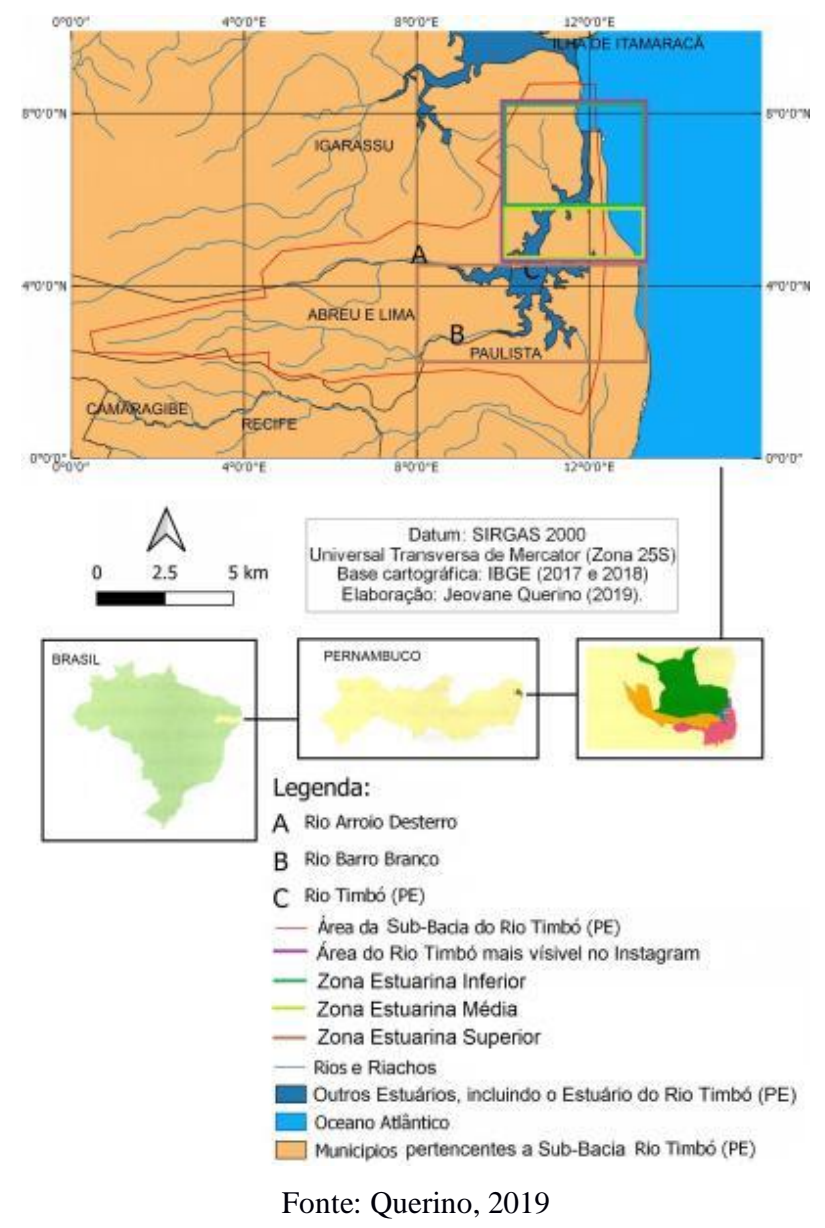

O rio Timbó nasce da confluência dos rios Barro Branco e Arroio Desterro, sendo um curso d'água conhecido pela presença significativa, em suas margens, da vegetação de mangue e restinga, contando, no seu entorno, com reservas ambientais estaduais e municipais, bem como atividades turísticas, pesqueiras, industriais, comerciais e urbanas. 
Por conta de uma série de atividades e equipamentos que potencializam o turismo no rio Timbó, vale ressaltar que este rio e suas margens (por se localizarem na região turística denominada pela CONDEPE/FIDEM-2011 como Costa Náutica e Coroa do Avião) notabilizam-se, devido à turistificação - que é "um processo em que o espaço é transformado para fins e usos voltados para a realização das atividades ligadas ao turismo" (VIEGAS, 2005, p. 79) - e, mais recentemente, pela estetização por meio do Instagram, conforme discutir-se-á mais adiante.

O rio Timbó se torna espaço cada vez mais visado pelas empresas turísticas, tais como marinas e hotéis, bem como é visibilizado enquanto rio estetizado em fotos no Instagram, sendo este aplicativo um incentivo às práticas turísticas e comerciais no rio e suas margens, de forma que estas atividades são observadas nas imagens postadas no aplicativo.

Em todas as imagens postadas no Instagram, referentes ao rio Timbó (como, por exemplo, pode-se ver nas Figuras 2 e 3), foram analisadas e estudadas:

- As demarcações hidroterritoriais dos discursos fotográficos dos usuários do Instagram sobre o rio Timbó-PE;

- A estetização das paisagens nas postagens do Instagram sobre o rio e suas margens.

Figuras 2 e 3: Seleção de imagens geolocalizadas no link Rio Timbó - Maria Farinha e Rio Timbó: como funciona a geolocalização

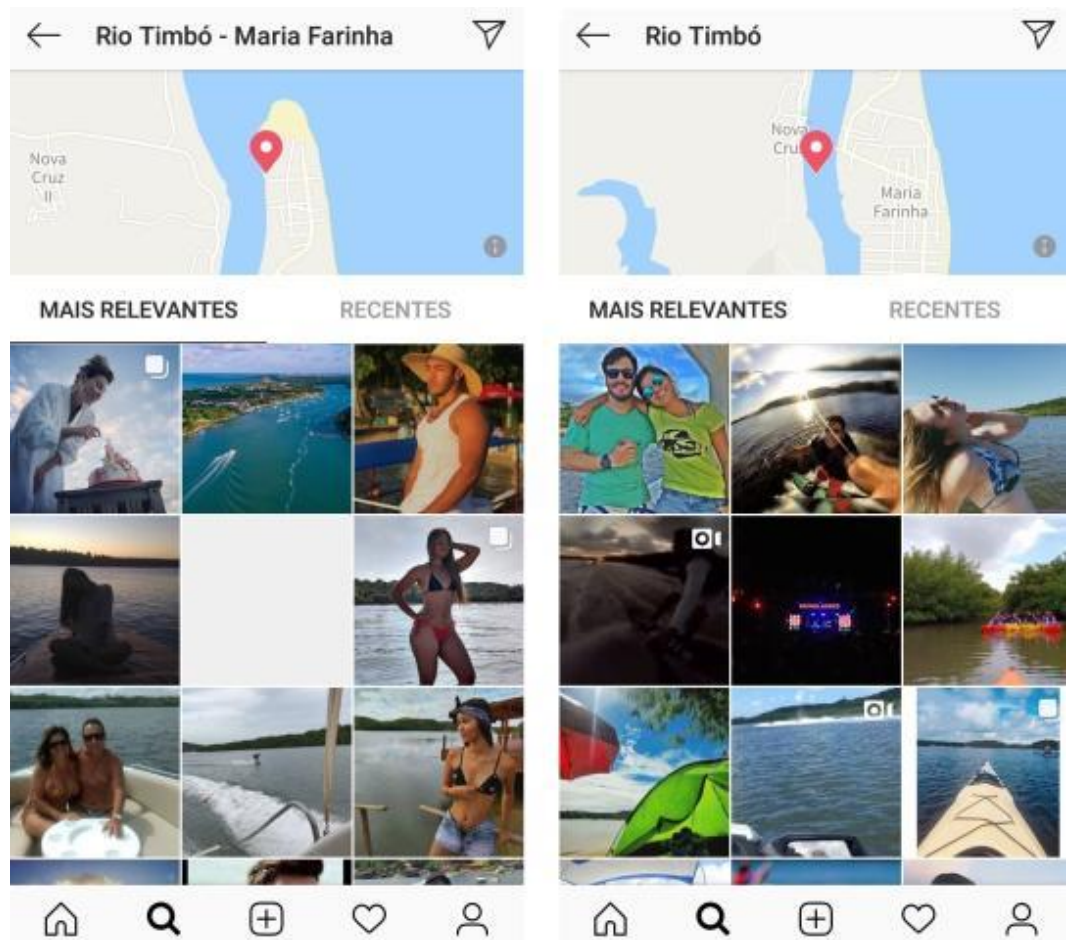

Fonte: Instagram, pesquisa em 30 de junho de 2019, com fotos de diversos usuários 
Estes mosaicos instagramáveis caracterizam como ocorrem postagens das fotos dos perfis de usuários, em que eles adicionaram a localização que desejaram para colocar em evidência; por outro lado, ao agrupá-las, o aplicativo forma mosaicos com imagens dos mais diversos usuários, que são geolocalizadas.

\section{CARACTERÍSTICAS DO APLICATIVO INSTAGRAM}

O Instagram é uma rede social que chegou à marca de 29 milhões de usuários no Brasil em $2015^{2}$, contando com a publicação de postagens de fotos e vídeos instantâneos sobre coisas, espaços e corpos (SALAZAR, 2017). Sendo bastante popularizada no Brasil, a rede tem, com isso, colocado em pauta a estetização das paisagens (LIPOVETSKY e SERROY, 2015) como um fenômeno mundial que vem se construindo pelas imagens e pelas realidades materiais que elas refletem, representando o cotidiano e o efêmero. Algumas postagens de fotos, como se verá ao longo deste trabalho, são influenciadas pela atual fase do capitalismo, caracterizado por ser artista ou criativo transestético, relacionando-se ao conceito de território e paisagem. $\mathrm{O}$ Instagram gera o consumo de imagens, criando paisagens econômicas, mundiais e mercantis (LIPOVETSKY e SERROY, 2015).

Atualmente, as imagens do aplicativo estão inseridas no "excesso na fotografia vernacular digital, a partir da ideia de que os dispositivos fotográficos contemporâneos e os mecanismos de compartilhamento [criaram] um espaço de hiperconsumo de imagens no Instagram, alavancado pelas lógicas do consumismo na sociedade" (SALAZAR, 2017, p. 14). Isto nos leva a refletir que, aliado à reflexão de Lipovetsky e Serroy (2015), classifica-se o Instagram como uma ferramenta online de consumo e produção de imagens postadas, curtidas, incentivadas pela publicidade, que divulgam e conformam paisagens, estetizando-as.

Na divulgação de imagens formam-se verdadeiros mosaicos, e, quando são utilizadas as hashtags (\#) e as ferramentas de geolocalização nas fotos no aplicativo (Figuras 4 e 5), estimulam a divulgação e o consumo das imagens, moldando discursos fotográficos das vivências das pessoas, que tiram fotos do rio e suas margens e as postam no aplicativo.

\footnotetext{
${ }^{2}$ Segundo dados recentes da Revista Exame (2019), o Brasil, em 2019, tem mais de 66 milhões de usuários do Instagram, sendo o segundo país com maior número de adeptos, ficando atrás apenas dos EUA, que tem mais de 110 milhões.
} 
Figuras 4 e 5: Ferramenta de Geolocalização e de Procura das Hashtags referentes ao rio Timbó-PE

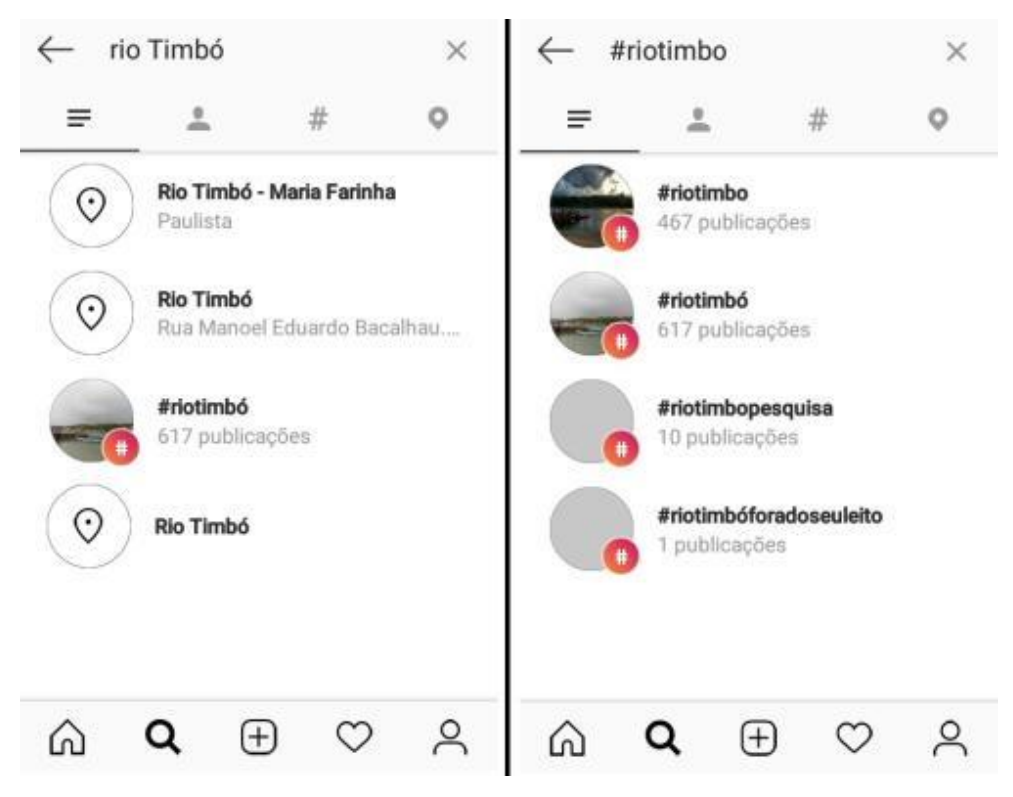

Fonte: Instagram, pesquisa de 01 de março de 2019

\section{O PODER SIMBÓLICO NOS DISCURSOS FOTOGRÁFICOS DO INSTAGRAM E AS CONCEPÇÕES DO HIDROTERRITÓRIO DO RIO TIMBÓ}

O conceito de hidroterritório é um desdobramento do território, e pode ser aprimorado, de forma salutar, na análise do poder simbólico e sua relação com a água (QUERINO e MACIEL, 2018). Aqui trata-se de um conceito mobilizado a partir da construção discursiva e da apropriação simbólico-cultural da água, ou seja, do espelho d’água do estuário do rio Timbó. Desta forma, o hidroterritório possui uma relação com o poder simbólico que o demarca, pois seriam as fotos instagramáveis do rio Timbó e suas margens que delimitariam o hidroterritório instagramável do estuário, visibilizando a subjetividade envolvida nos discursos fotográficos do aplicativo (BIANCHI, 2017) e na apropriação simbólica do rio pelos usuários e pelo próprio aplicativo. Subjacente a esta questão de apropriação simbólica estão as diferentes possibilidades econômicas e formas de acesso ao espaço, bem como o uso de aparelhos celulares.

Com isso, a construção discursiva e apropriação simbólica do hidroterritório é definida pela relação com as subjetividades que o delimitam, mas também pelas relações de poder 
simbólico, que é o "poder de constituir o dado pela enunciação, de fazer ver e fazer crer, de confirmar ou de transformar a visão do mundo e, deste modo, a ação sobre o mundo, portanto o mundo" (BOURDIEU, 2001, p. 14). As imagens analisadas revelam que as pessoas que frequentam e "retratam" aquele rio estão ligadas a práticas de turismo e lazer, representando, portanto, a parcela da sociedade dotada de poder para construir uma visão instagramável do hidroterritório.

Desta forma, o poder simbólico se constrói a partir das subjetividades intrínsecas ao hidroterritório, delimitando-o através dos discursos fotográficos do Instagram, que são dados pela enunciação, ou seja, a postagem e a visibilidade no aplicativo, bem como a apropriação simbólica do espaço por parte de adeptos da cultura digital, partindo da enunciação dos discursos fotográficos no aplicativo de compartilhamento de fotos e como eles transformam a visão sobre o rio Timbó.

\section{O CONTEXTO DA SOCIEDADE DO ESPETÁCULO NO RIO TIMBÓ E SUAS MARGENS}

No contexto de postagens de fotos que visibilizam o estuário do rio Timbó temos que, no contexto da sociedade atual - caracterizada por Guy Debord (1997), como sociedade do espetáculo, "que modela tudo o que a cerca [construindo] uma técnica especial para agir sobre o que dar sustentação a essas tarefas: o próprio território” (p. 112) - é possível perceber sua relação íntima com o acesso a dispositivos digitais e o domínio da técnica fotográfica exposta no Instagram, que se exerce na construção do território do rio em estudo.

Desta maneira, o espetáculo, produzido pela exibição das imagens do Instagram sobre o rio Timbó atrela-se ao discurso publicitário e turístico de alguns usuários (Figura 6), acabando por ser caracterizado pelo: "momento em que a mercadoria ocupou totalmente a vida social" (DEBORD, 1997, p. 30). Portanto essa ferramenta digital pode ser capaz de mercantilizar certas paisagens, territorializando-as por meio dos discursos fotográficos instagramáveis e através da apropriação da imagem desses espaços (LIPOVETSKY e SERROY, 2015; SALAZAR, 2017).

Tendo em vista o contexto em que se pode encontrar algumas imagens do Instagram, é possível dizer que nem todos os usuários do aplicativo mercantilizam este espaço estuarino do rio Timbó, mas que algumas marinas e hotéis se utilizam do rio e de algumas fotos deste curso d'água. Quer dizer, há uma estetização para prover o espetáculo de publicidades que: "não é 
um conjunto de imagens, mas uma relação social entre pessoas, mediada por imagens" (DEBORD, 1997, p. 14). Desta forma, é produzido um espetáculo de publicidades mediado pelas imagens e a construção de uma mercantilização do rio Timbó para atividades atreladas ao comércio turístico e de lazer (Figura 6).

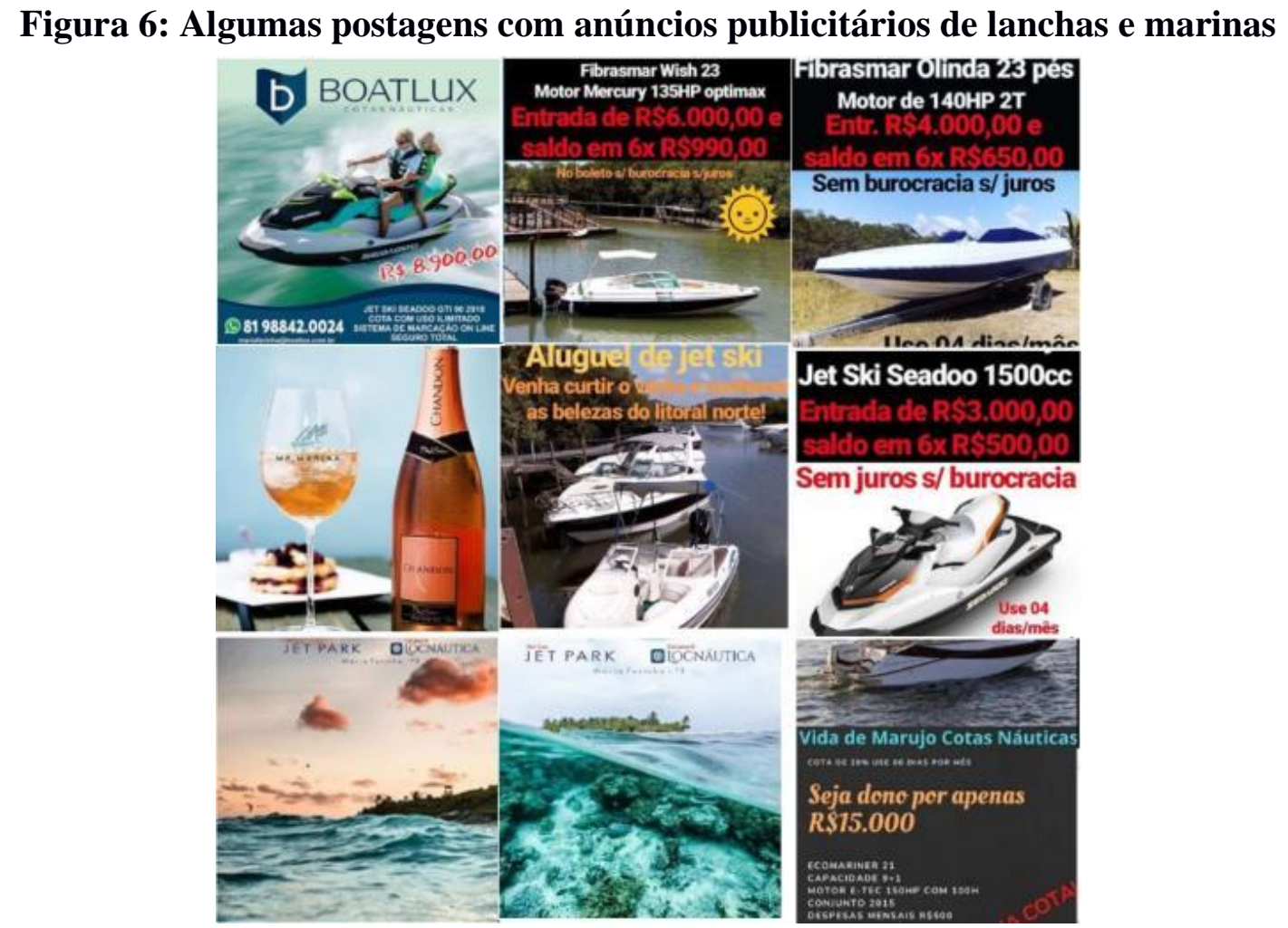

Fonte: Instagram, pesquisa de 06 de março de 2019, com algumas fotos extraídas da \#riotimbo

Algumas postagens de usuários do Instagram, nesse sentido, exercem, no contexto da sociedade do espetáculo (DEBORD, 1997), influência concreta sobre o estuário do rio Timbó, transformando-o em mercadoria, com a exibição de imagens e propagandas de marinas e lanchas (Figura 6), promovendo a exibição de produtos, anúncios de vendas de lanchas, jetskis, caiaques e de bebidas, de modo a favorecer a atração de usuários do aplicativo para certas partes do rio Timbó e de suas margens, enquanto outras permanecem invisibilizadas.

Há, ainda, um fenômeno de recomposição territorial: nem todas as fotos da Figura 6 acima foram de fato capturadas no rio Timbó; algumas representam a ilha Coroa do Avião, outras o Pontal de Maria Farinha, bem como outras têm origem desconhecida. Isto se deve ao padrão estético produzido por alguns usuários do Instagram, que constroem imagens para a mercantilização do rio Timbó, no sentido de vender um padrão estético relacionado ao que se espera de atividades de sol, mar e rio. Tal impulso de venda proporciona uma produção de 
imagens estetizadas para a atratividade turística do local, elegendo padrões estéticos dominantes (LIPOVETSKI e SERROY, 2015) e numa produção de imagens massificadas, sintoma da indústria cultural que está intrínseca ao capitalismo artista transestético (LIPOVETSKI e SERROY, 2015).

Desta maneira, a apropriação simbólica, por parte de alguns usuários do Instagram, encontra-se atravessada pelo contexto da sociedade do espetáculo, que transforma as paisagens, em mercadoria (MENESES, 2002), sendo que isso se compreende através das relações políticas e simbólicas que as imagens do aplicativo estabelecem com este espaço, gerando a demarcação hidroterritorial e a turistificação daquele espaço.

A utilização do Instagram pelo turismo acelera certo processo de apropriação simbólica do hidroterritório e das paisagens, devido à construção discursiva atrelada à atratividade turística do lugar, que é um fator determinante na demarcação espacial do rio Timbó, pois a relação entre estética e política que se estabelece, promove o valor estético dado pelo turismo ao rio Timbó e suas margens.

Como atesta Torres (2007), o capitalismo "está empenhado em promover hidroterritórios privados de forma que a sociedade reconheça a água como mercadoria", pois os territórios aquáticos participam de relações políticas e estéticas. Assim, empresas do turismo tentam legitimar a privatização de áreas do rio Timbó, colocando ao longo deste corpo d'água lanchas e marinas privadas, nas quais para se ter acesso é preciso pagar valores significativos para se praticar o turismo.

\section{A ESTETIZAÇÃo dAS PAISAGENS DO RIO TIMBÓ E SUAS MARGENS PELA PREFEITURA DA CIDADE DO PAULISTA}

Vale destacar que os flashes das paisagens do rio geralmente são tirados de locais dentro das marinas, hotéis, lanchas, barcos e catamarãs, fortalecendo o caráter privado destes espaços, sendo necessário o pagamento de taxas nas marinas para o acesso aos locais desfrutados pelos turistas que ao utilizarem do Instagram, tornam-se Instagramers (usuários do Instagram), representando as paisagens do rio Timbó e suas margens. Contudo, há também a participação de entes estatais neste processo, como as prefeituras.

Com isso, temos que as representações dos usuários do Instagram marcam os momentos, em que eles vivenciam com o rio, de forma a usar as paisagens, misturando suas fotos com as 
propagandas de empresas que ficam no entorno do rio e publicidade institucional, formando mosaicos de fotos atravessados por relações sociais, econômicas, culturais e individuais com o Instagram.

Ainda sobre a paisagem, adotando a concepção de Jean-Marc Besse (2006), é possível entender que a mesma pode ser representada e é um discurso que leva a compreender a vida humana e sua dimensão cultural e espacial. Isto fica patente no rio Timbó e suas margens, onde as pessoas, empresas e governos usam o Instagram para gerar uma dimensão discursiva e representativa, formando certas imagens das paisagens representadas, enquanto outras permanecem não-instagramáveis.

Com isso, pode-se ver nas imagens instagramáveis:

a estética e o lúdico, o festivo e o consumo hedonista se tornaram vetores de configuração de um novo ambiente urbano. Hoje a própria cidade se empenha em se construir como centro do lazer, do consumo e do divertimento, e isso mediante um trabalho de reabilitação e de estetização da paisagem urbana, mediante operações destinadas a reservar o centro das cidades aos pedestres e recuperar as margens fluviais, por meio de atividades de animação diversas, de jogos de imagens e de luzes destinados a criar um ambiente mais atraente e bonito para uma clientela de turistas e consumidores de lazer (LIPOVETSKY e SERROY, 2015, p. 322 , grifo nosso)

Desta forma, como Lipovetsky e Serroy (2015) apontam, a estetização das paisagens, principalmente das margens fluviais, é de suma importância para criar a atratividade e a beleza para que turistas e consumidores do lazer aproveitem da própria paisagem, que os atraem. É exatamente o que faz a prefeitura do Paulista em relação ao estuário estudado. Nisso, os usuários do Instagram, muitas vezes, são os turistas e consumidores de lazer que tiram suas fotos no rio, reforçando formas de visibilizar e estetizar paisagens. Deste modo, constrói-se um espaço atrativo, favorecendo cada vez mais as atividades das marinas e resorts ao redor do rio, muitas das vezes em associação com o poder público.

Esse fenômeno da reabilitação e estetização das paisagens urbanas se dá muito presente nas cidades ao redor do rio Timbó, pois cada vez mais as prefeituras e o Estado de Pernambuco vêm criando mecanismos de políticas para o turismo; a exemplo disso, temos a Prefeitura da Cidade do Paulista que tem feito ações junto à EMPETUR (Empresa Pernambucana de Turismo), visando promover projetos de desenvolvimento de atividades turísticas no Pontal de Maria Farinha, na foz do rio Timbó (PREFEITURA DO PAULISTA, 2016). 
Porém, há de se observar nas fotos do Instagram, que a Prefeitura da Cidade do Paulista posta fotografias do pontal e do rio, mas existe, por parte do ente público, um esquecimento da área quando se trata de políticas públicas e comunidades ribeirinhas (Figura 7). Todavia, quando são políticas votadas do turismo, há certa facilitação para as marinas, empresas e resorts privados, sendo possível observar, através das fotos e seus comentários, as reclamações dos usuários do Instagram a respeito do esquecimento da área do Pontal de Maria Farinha e setores do rio Timbó (lixo, poluição, falta de saneamento e organização do espaço).

\section{Figura 7: Reclamação numa das Imagens postadas pela Prefeitura da Cidade do}

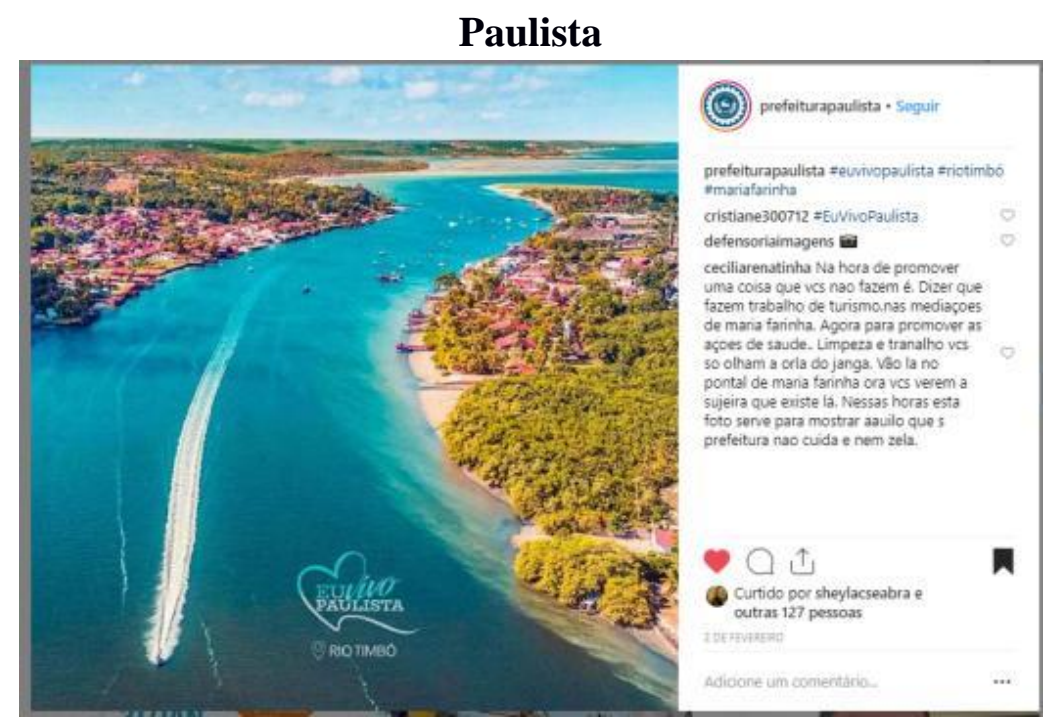

Fonte: Instagram, pesquisa de 07 de março de 2019, extraída do Usuário @ prefeiturapaulista

É possível observar na postagem acima, um descompasso entre o que a Prefeitura realiza, enquanto políticas públicas para a população que mora às margens do rio Timbó e a estetização que ela faz das paisagens do mesmo rio pelo Instagram. A realização de políticas que favoreçam os locais, como observado nesta postagem, parece ser um motivo de reclamação de uma moradora, o que torna a ferramenta digital viabilizadora das contradições sociais e políticas do local, de forma que se percebe o desacerto, observado nas imagens, entre a estetização e a realização de políticas para os habitantes daquele hidroterritório.

A estetização do rio Timbó e de suas margens por parte de imagens postadas pela Prefeitura da Cidade do Paulista (exemplos na Figura 7), traz à tona qual é a motivação decisiva para mobilizar as paisagens do rio: garantir maior apropriação simbólica do hidroterritório com o intuito de criar discursos fotográficos que viabilizem as atividades turísticas e de lazer naquele estuário, de forma a facilitar para o capital privado a instalação de diversos negócios. Assim, a 
construção do olhar que se dá através das fotos do Instagram a partir do usuário @ prefeiturapaulista enaltece o discurso turístico e publicitário, alicerçado ao discurso da prefeitura, que cria subjetividades domesticadas (BIANCHI, 2017; GUATTARI, 1992), pois incorpora na estetização das paisagens do rio Timbó a representação das geografias utilizadas pela publicidade estatal, que atua na promoção do turismo e do lazer.

Conforme se pode observar no mosaico de imagens da Figura 8, oriundas do perfil de usuário do Instagram da Prefeitura do Município do Paulista, há uma ênfase em representar esteticamente a área do Pontal de Maria Farinha (Figura 8, imagens A, B, D e F), que está entre a foz do rio Timbó e o oceano Atlântico. Tal porção do espaço apresenta características naturais que são valorizadas e estetizadas nas fotos da campanha fotográfica e digital promovida pela Prefeitura, sendo responsável pela sedução estética no município e em torno da atratividade turística que se exerce, apropriando-se simbolicamente das amenidades ambientais e paisagísticas do que está próximo à foz do rio Timbó.

\section{Figura 8: Mosaico com Algumas Imagens do rio Timbó e suas margens postadas pela Prefeitura da Cidade do Paulista-PE}

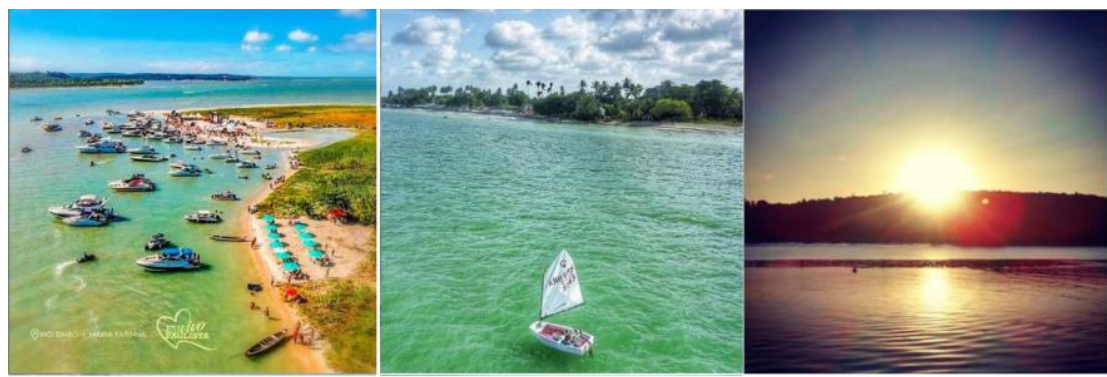

A

B

C

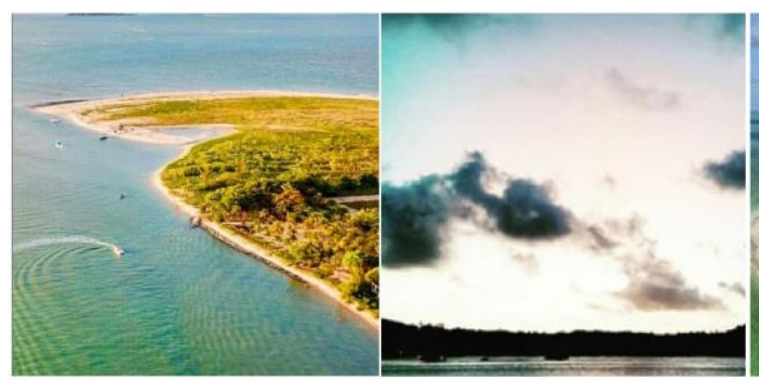

$\mathrm{D}$
E

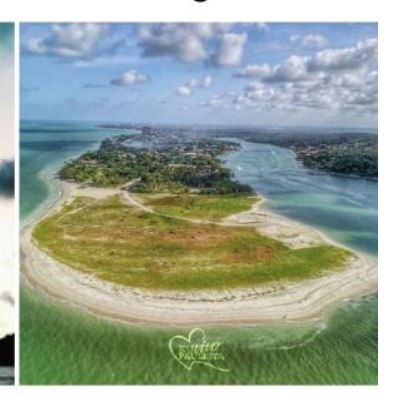

$\mathrm{F}$

Fonte: Instagram, pesquisa de 01 de março de 2019, com fotos do usuário @ prefeiturapaulista

As paisagens da Figura 8 são consideravelmente estetizadas, mostrando o verde das restingas e dos manguezais próximos às margens do rio, misturando-se nas fotos com a coloração verde e azul das águas do rio e do oceano, para demarcar, a partir da representação 
das paisagens, as características estéticas, relacionadas aos aspectos naturais e turísticos do rio e suas margens, servindo, também, de divulgação da atividade turística na cidade do Paulista.

Ainda é possível perceber como as imagens instagramáveis, através do seu formato, quadrado, comunicam a representação da estetização das paisagens justamente para uma atratividade turística, que se torna uma estratégia política de sedução estética empregada pelas imagens divulgadas pela prefeitura, tendo em vista o interesse turístico e estético na área, onde há marinas, hotéis, casas de veraneio e empresas de aluguel de equipamentos náuticos e embarcações.

Existem representações de momentos (Figura 8, Imagens: C e E), que funcionam na tentativa de apresentar a estetização do pôr do sol na área; com isso se apropria simbolicamente da beleza natural que representa o poente, para transformá-lo num discurso fotográfico apropriado para satisfazer a atratividade turística do local, demarcando a apreciação das pessoas, seduzindo-as para atrair mais visitantes.

A Prefeitura da Cidade do Paulista, enquanto instituição do Poder Público Municipal e instituição do Estado, revela em seu perfil do Instagram o quão essa instituição é capaz de formar "quadros sociais da memória, isto é, essas referências propriamente sociais com relação às quais organizamos nossa vida privada" (BOURDIEU, 2014, p. 39), que funcionam de certa maneira como princípios de visão e di-visão das formas simbólicas de estruturação do pensamento em sociedade (MONTEIRO, 2018).

Desta maneira, o pensamento que estrutura o Estado, representado pelas postagens de fotos pelo perfil da prefeitura municipal, vai-se estruturando a partir das fotos das paisagens do rio Timbó postadas no Instagram, concebendo uma visão do local recortada e dividida pela exibição das formas simbólicas, que estrutura o pensamento daqueles que veem as imagens e são seduzidos esteticamente a visitarem o rio e suas margens, numa espiral que se retroalimenta das imagens privadas e empresariais.

Toda essa formação de quadros sociais e geográficos de memória vai organizando a vida privada das pessoas a serem atraídas para o rio, direcionando e mobilizando, amparando não só o discurso publicitário e turístico, mas formando concepções sobre o rio e suas margens, concepções estas, efêmeras e cotidianas, a depender do papel social que as pessoas ocupem, seja trabalhando no rio e suas margens, seja visitando esta área para o turismo. 


\section{A ESTETIZAÇÃO DAS PAISAGENS A PARTIR DAS REPRESENTAÇÕES DO RIO TIMBÓ E SUAS MARGENS FEITAS POR PERFIS INDIVIDUAIS}

Paisagens são instituídas por usuários do Instagram através das relações que se estabelecem no cotidiano e em visitas efêmeras. Visualizadas através do aplicativo, representações fotográficas das paisagens estabelecem uma construção discursiva e fotográfica do rio Timbó e suas margens, delineando hidroterritórios. Ou seja, existem subjetividades intrínsecas que são mediadas pelo aplicativo nas relações entre o rio e os usuários individuais do Instagram. Isto é, tais mediações viabilizam as vivências subjetivas (conforme se vê na Figura 9, abaixo).

\section{Figura 9: Mosaico com Algumas Fotos de Diversos Usuários do Instagram que foram}

\section{Geolocalizadas no Aplicativo}

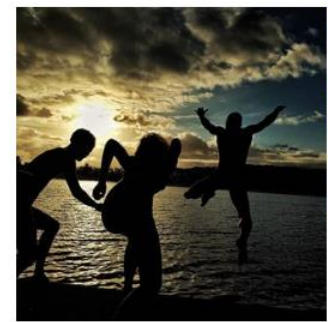

A

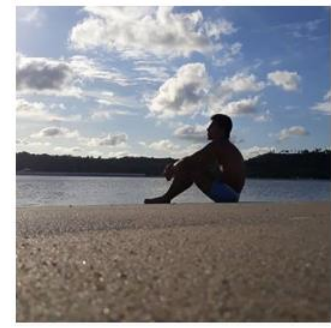

D

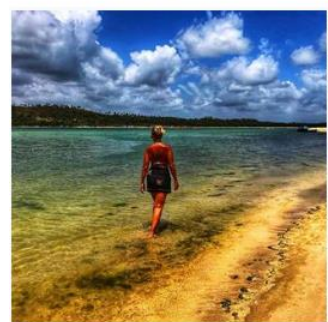

G

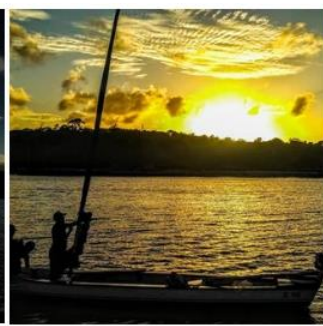

B

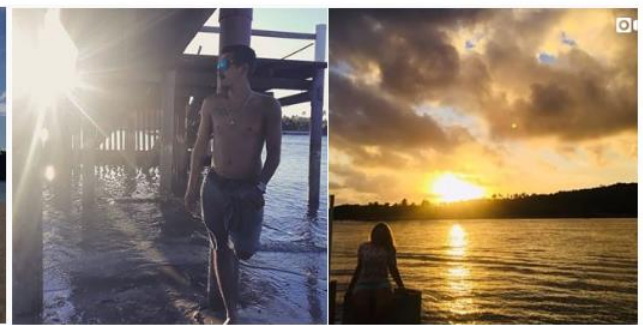

E

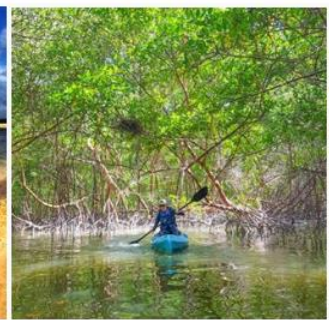

$\mathrm{H}$

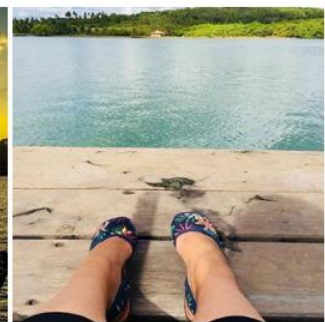

C

$\mathrm{F}$

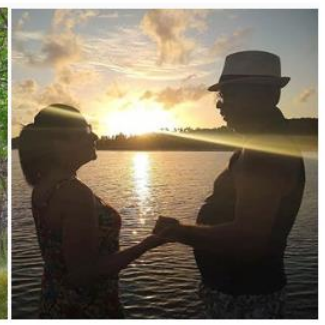

I

Fonte: Instagram, pesquisa de 09 de março de 2019, com fotos de Usuários diversos, sendo fotos que utilizaram a ferramenta de Geolocalização: Rio Timbó - Maria Farinha

Continuando a análise da Figura 9, as vivências subjetivas que o Instagram viabiliza se relacionam aos usos que as pessoas fazem do rio Timbó para tirar fotos, representando seus sentimentos e emoções característicos do momento em que elas estão inseridas, ou seja, as 
situações efêmeras. Isto se deve não só às atividades turísticas que são representadas nas paisagens, mas se dá em relação à subjetividade representada fotograficamente no Instagram e como se constroem discursos fotográficos capazes de expressar valores e sentimentos relacionados às vivências das pessoas com o rio Timbó.

As representações fotográficas das paisagens no Instagram exprimem sentimentos relativos a momentos de diversão e comemoração (Figura 9, Imagens: A e I), encontros entre as pessoas (Figura 9, Imagens: A, B e I), pesca em um barco (Figura 9, Imagem B), momentos solitários de introspecção e de reflexão (Figura 9: Imagens: C, D, E, F e G) e de aventuras (Figura 9, Imagem: H). Desta forma, todos esses momentos traduzem representações fotográficas de uma certa porção do rio Timbó (hidroterritório turístico), que são efêmeras, pois não duram um longo período de tempo, mas que são rememoradas quando as pessoas visualizam suas fotos no aplicativo Instagram, como se fosse um álbum de família ou panfleto de viagem, que guarda/produz desejos de momentos felizes.

Porém, vale destacar como as fotos do Instagram aqui exemplificadas na Figura 9, exprimem a dimensão individual e privada da vida das pessoas e desta forma constroem discursos fotográficos através da relação com as paisagens relativas aos sentimentos de lembranças e afetos que o hidroterritório turístico do rio Timbó pode propiciar. Essas individualidades representadas nas fotos, onde grande parte das pessoas aparecem sozinhas (individualismo contemporâneo), exprimem a contemplação e uma afeição com o rio e suas margens, bem como uma admiração estética das pessoas com o rio.

A representação fotográfica e estetização das paisagens do rio revelam ainda sentimentos de aconchego, tão visibilizados na Figura 9, Imagem: I, que mistura discursos fotográficos de amor entre as pessoas e de afeição em querer estar no rio, tendo sentimentos amorosos um pelo outro. Desta maneira, a expressão de sentimentos que são possíveis de se visualizar, nestes momentos, é aquela de pessoas contemplando e vivenciando esteticamente o rio. Por outro lado, a captura disto pelas fotos no Instagram converge para atrair mais turistas a vivenciar experiências com o rio, consolidando o caráter daquele hidroterritório.

\section{CONSIDERAÇÕES FINAIS}

Buscou-se, neste trabalho, inter-relacionar os conceitos geográficos de hidroterritório e paisagem, geografando o Instagram e as suas fotos, para apontar o poder de visibilidade que este aplicativo de compartilhamento de imagens desvela em suas construções discursivas, 
apropriações simbólicas e com relação à estetização e representação das paisagens do rio Timbó e suas margens enquanto um espaço do turismo e lazer.

Discursos fotográficos digitais enaltecem fenômenos, momentos e vivências relacionados à estética e à política, compondo quadros geográficos (GOMES, 2017) que enunciam demarcações hidroterritoriais carregadas de subjetividades, capazes de formar concepções políticas e estéticas sobre o rio Timbó e suas margens. Portanto, este rio torna-se um hidroterritório instagramável para atividades de turismo, lazer e veraneio.

Desta forma, buscou-se refletir como a atratividade turística e a capacidade de sedução estética são induzidas politicamente através, por exemplo, das peças publicitárias de Marinas e da Prefeitura do Paulista. Ainda que haja a construção de representações fotográficas das próprias pessoas que usam, individualmente, o aplicativo Instagram, existe sim, um contraste com as propagandas de marinas e resorts. Tal contraste, contudo, integra-se a um certo discurso possível sobre o turismo de sol, mar e rio, bem como às vontades de paisagem dos turistas, num processo de retroalimentação.

Por fim, este trabalho mostra que o Instagram é uma ferramenta geográfica que demarca territórios, hidroterritórios e paisagens, de modo que participa das concepções espaciais simbólicas que interferem nas dimensões geográficas concretas. Assim, pode-se falar a partir do caso do rio Timbó em uma Geografia Instagramável, de ampla aplicação em outras situações.

Refletir sobre a forma de se utilizar o Instagram e outros aplicativos da era digital para desvelar geografias existenciais está na ordem do dia, uma vez que cada vez mais espaços estão sendo produzidos e interpretados em torno de subjetividades intrínsecas à interatividade com as imagens, tais como a construção discursiva e fotográfica de hidroterritórios e paisagens aqui analisados.

\section{REFERÊNCIAS}

BESSE, Jean-Marc. Ver a terra: seis ensaios sobre a paisagem e a geografia. São Paulo, Editora Perspectiva, 2006.

BIANCHI, Ana C. M. Discurso fotográfico no Instagram: a cidade de Vitória sob o olhar de seus usuários. Dissertação (Mestrado em Comunicação e Territorialidades) - Centro de Artes, Universidade Federal do Espírito Santo. Vitória, 2017.

BOURDIEU, Pierre. O Poder Simbólico. Rio de Janeiro: Bertrand Brasil, 2001. 
1930-2002. Sobre o Estado: Cursos no Collège de France (1989-92). $1^{\text {a }}$ ed. São Paulo: Companhia das Letras, 2014.

CONDEPE/FIDEM, Agência Estadual de Planejamento e Pesquisas de Pernambuco. Pernambuco em mapas. Coordenação de Ruskin Marinho de Freitas e Kamila Soares de Arruda Santos. Recife, 2011.

DEBORD, Guy. Sociedade do espetáculo. Rio de Janeiro: Contraponto, 1997.

GOMES, Paulo César da Costa. Quadros geográficos: uma forma de ver, uma forma de pensar. Rio de Janeiro: Bertrand Brasil, 2017.

GUATTARI, Félix. Caosmose: um novo paradigma estético. São Paulo (SP): Editora 34, 1992. INSTAGRAM. Geolocalização do Rio Timbó - Maria Farinha. Disponível em: $<$ https://www.instagram.com/explore/locations/301131544/rio-timbo-maria-farinha/>. Acesso por último em: 02 de Outubro de 2019.

Geolocalização do Rio Timbó. Disponível em: <https://www.instagram.com/explore/locations/340507082/rio-timbo/>. Acesso por último em: 02 de Outubro de 2019.

Perfil de Usuário da Prefeitura da Cidade do Paulista ( @ prefeiturapaulista). Disponível em: <https://www.instagram.com/prefeiturapaulista/>. Acesso por último em: 02 de Outubro de 2019.

\#riotimbo.

Disponível

em: $<$ https://www.instagram.com/explore/tags/riotimbo/>. Acesso por último em: 02 de Outubro de 2019.

LIPOVETSKY, Gilles; SERROY, Jean. A Estetização do Mundo: viver na era do capitalismo artista. $1^{\mathrm{a}}$ ed. $2^{\mathrm{a}}$ reimpr. São Paulo: Companhia das Letras, 2015.

MENESES, Ulpiano T. Bezerra. A Paisagem como fato cultural. In: YÁZIGI, Eduardo (Org.). Turismo e Paisagem. São Paulo: Contexto, 2002, p. 29 - 64.

OLIVEIRA BARBOSA, Maria J. Estudos sedimentológicos do estuário do rio Timbó-PE. Dissertação (Mestrado). Programa de Pós-Graduação em Geociências, Universidade Federal de Pernambuco, Recife, 2006.

PREFEITURA DO PAULISTA. Paulista na rota da regionalização do turismo em Pernambuco [09 de Março de 2016]. Paulista, PE: Site da Prefeitura da Cidade do Paulista. Disponível 
em:<http://www.paulista.pe.gov.br/site/noticias/detalhes/1923>. Acesso em: 12 de Março de 2019.

Paulista cria reservas para proteger os manguezais e espécies ameaçadas [27 de Julho de 2018]. Paulista, PE: Site da Prefeitura da Cidade do Paulista. Disponível em: <https://www.paulista.pe.gov.br/site/noticias/detalhes/4953>. Acesso em: 30 de Junho de 2019.

QUERINO, Jeovane S. F. Por uma Geografia Instagramável: As Representações e Concepções do Rio Timbó (PE) e suas Margens. Orientador: Caio Augusto Amorim Maciel. Monografia (Graduação) - Universidade Federal de Pernambuco, Centro de Filosofia e Ciências Humanas. Departamento de Ciências Geográficas, 2019. ; MACIEL, C. Análise Geopoética do Álbum Salve o São Francisco de Geraldo Azevedo e Parceiros: Reflexões sobre o rio São Francisco. Revista Brasileira de Meio Ambiente, RVBMA, v. 2, p. 2-17, 2018.

REVISTA EXAME. Estes são os dez países que mais usam o Instagram. [12 de maio de 2019]. Site da Revista Exame. Disponível em:<https://exame.abril.com.br/tecnologia/estessao-os-dez-paises-que-mais-usam-o-instagram/> . Acesso em: 29 de Outubro de 2019.

SALAZAR, Manuela. Mundos-mosaicos: a estetização do cotidiano no Instagram. Universidade Federal de Pernambuco, Dissertação (Mestrado), Centro de Artes e Comunicação. Comunicação, Recife, 2017.

SILVEIRA, Vanessa R. Corpos e beleza no Instagram: estetização em busca de likes. Dissertação (Mestrado em Comunicação e Semiótica) - Programa de Estudos Pós-graduados em Comunicação e Semiótica, Pontifícia Universidade Católica de São Paulo, São Paulo, 2017. TORRES, Avaní Terezinha. Hidroterritórios (novos territórios da água): os instrumentos de gestão dos recursos hídricos e seus impactos nos arranjos territoriais. Universidade Federal da Paraíba, Dissertação (Mestrado em Geografia), João Pessoa, 2007.

VIEGAS, Jeanete M. Turistificação de áreas rurais e perspectivas de desenvolvimento socioespacial na Zona da Mata Norte de Pernambuco. Dissertação (Mestrado). Programa de Pós-Graduação em Geografia, Universidade Federal de Pernambuco, Recife, 2005. 